\title{
An analysis of inherited factors affecting the sex ratio in the rice weevil, Sitophilus oryzae L.
}

\author{
Graham J. Holloway
}

Population Biology Laboratory, Department of Pure
and Applied Zoology, University of Reading,
Whiteknights, Reading, Berkshire, England RG6 2AJ.

\begin{abstract}
Observations of a significant female bias in one geographical strain of the rice weevil, Sitophilus oryzae L., stimulated a detailed investigation of sex ratio in three geographical strains. Sex ratios from intra-strain crosses were not usually biased, but certain inter-strain crosses were consistently associated with female biased sex ratios. Foodtype did not affect the sex ratio. Sex ratio bias was continued through generations and reciprocal crosses produced dissimilar sex ratios. A model of the genetic basis of sex ratio determination in $S$. oryzae was developed involving the interaction of a non-chromosomal, maternally inherited factor and a $\mathrm{Y}$-linked factor. Evidence supporting $\mathrm{Y}$ chromosome involvement in the model and the similarity of certain features of the model to hybrid disgenesis in Drosophila were discussed.
\end{abstract}

\section{INTRODUCTION}

The sex ratio is an important fitness character of any sexually reproducing organism. Fisher (1930) first pointed out that the sex ratio would be determined by the relative amounts of effort devoted to sons and daughters by the parents. If sons and daughters require the same expenditure of time and activity by the parents before the offspring become independent, the optimum sex ratio would be $1: 1$ in an idealised random mating population. However, in some species, although sons and daughters require the same amount of energy expenditure by the parents, the primary sex ratio is biased in favour of females. Hamilton (1967) noted that such bias often occurs when males compete with siblings more than with unrelated males for the same group of females; Hamilton called the phenomenon local mate competition and showed that the optimum sex ratio is female biased when males compete for mates with relatives. Extreme examples of sex ratio bias occur in some groups of arrhenotokous arthropods and such examples are usually interpreted as resulting from local mate competition (Hamilton, 1967; Charnov, 1982).

The sex ratio of the rice weevil, Sitophilus oryzae L., has been reported as not deviating significantly from 1:1 (e.g., Richards, 1947; Evans, 1977), but Shazali (1982) noted that the sex ratio in a population of $S$. oryzae from Hyderabad, India, was significantly biased in favour of females. The work described here analyses the sex ratio in the Indian strain (I) used by Shazali (1982) and in two geographical strains of $S$. oryzae collected in St. Augustine, Trinidad (T) and Tanzania, Africa (A). The aim of the experiments was to determine whether different geographical strains produced different sex ratios and what the genetic basis of such differences was.

\section{EXPERIMENTAL DETAILS}

Experimental grain was disinfested at a temperature of $80^{\circ} \mathrm{C}$ for 4 hours (Coombs et al., 1977). Grain moisture content was then allowed to equilibrate in a constant temperature and humidity $(\mathrm{CTH})$ room at $30^{\circ} \mathrm{C}$ and 70 per cent r.h.. The grain was placed in large plant propagators to a depth of $2-3 \mathrm{cms}$ and left in the $\mathrm{CTH}$ room for a period of two months prior to the experiments to equilibrate (Pixton and Warburton, 1968).

All female insects used were virgin. The collection of virgin $S$. oryzae is easy since females will not mate until 48 hours have elapsed from adult 
emergence from grain (Singh and Soderstrom, 1963 ). Sexing was performed under $\times 12$ magnification using sexually dimorphic rostrum characters (Halstead, 1963).

\section{(i) Experiment 1: Sex ratio variation on wheat}

The three strains were paired up in all nine possible strain $\times$ strain combinations. A male and female were placed in a $50 \mathrm{~mm}$ high $\times 25 \mathrm{~mm}$ diameter glass tube with approximately $3 \mathrm{~g}$ of wheat and capped with a perforated plastic top. Each strain $\times$ strain combination was replicated 12 times. The insects were allowed to oviposit for 20 days and then removed from the tubes. The tubes were inspected daily after the 28 th day from the beginning of the experiment. Emerging offspring were removed from the tubes and sexed. For each strain $\times$ strain combination, six of the 12 replicates were selected at random; three sib:sib pairings were set up for each chosen replicate and allowed to oviposit for 20 days in order to produce F2 offspring.

\section{(ii) Experiment 2: Sex ratio in relation to food}

The three strains were paired up in all nine possible strain $\times$ strain combinations. A male and a female were placed in a $50 \mathrm{~mm} \times 25 \mathrm{~mm}$ glass tube with $3 \mathrm{~g}$ of either wheat, sorghum or yellow split-pea. For each food, six replicates of each strain $\times$ strain combination were set up. The insects were allowed to oviposit for one week before being transferred to another tube containing $3 \mathrm{~g}$ of fresh food and the procedure was continued until the insects died of old age. At no time were the insects transferred to a different foodtype. The reason why insects were transferred to fresh food weekly was that this experiment was part of a broader investigation of life history characters in relation to age (Holloway, 1984). In order to make the data comparable with experiment 1 , offspring from the first 21 days of oviposition were combined. Newly emerging offspring were sexed but not retained.

\section{RESULTS}

\section{(i) Sex ratio data}

More than half of the crosses showed significant differences between replicate heterogeneity for sex ratio and therefore the usual binomial distribution variance could not be used to calculate confidence intervals for the strain $\times$ strain combination sex ratios. Therefore, the following expression was used which does not assume that the data between replicates is binomially distributed (J.H. Roger, pers comm):

$$
\text { Var. } \hat{R}=\frac{N}{\left(\sum_{i=1}^{N} y_{i}\right)^{2}}\left(S x x-2 \hat{R} S x y+\hat{R}^{2} S y y\right)
$$

where

$x_{i}=$ number of males in $i$ th replicate,

$y_{i}=$ total number in $i$ th replicate,

$N=$ number of successful replicates,

$\hat{R}=$ sample sex ratio (proportion male)

$S x x=$ corrected sum of squares of $x_{i}$,

$S y y=$ corrected sum of squares of $y_{i}$,

$S x y=$ corrected sum of cross products of $x$ and $y$.

Using expression (1), the null hypothesis $H_{0}: \hat{R}=0.5$ was tested against each strain $\times$ strain combination sex ratio. The sex ratios from the 1 st and 2 nd generations (experiment 1 ) are shown in table 1.

Table 1 Sex ratios (proportion male) in the F1 and F2 (Experiment 1 ). The stars represent significance levels of deviations from $\mathrm{Ho}: \hat{\mathrm{R}}=0.5\left(^{*}: p<0.05: * *: p<0.01, * * *: p<0.001\right)$

a) Sex ratios in $F 1$

\begin{tabular}{llll}
\hline & \multicolumn{3}{c}{ Female parent } \\
\cline { 2 - 4 } Male & $\mathrm{T}$ & $\mathrm{I}$ & $\mathrm{A}$ \\
\hline $\mathrm{T}$ & 0.471 & $0.463^{*}$ & $0.410^{*}$ \\
$\mathrm{I}$ & $0.343^{* * * *}$ & 0.466 & 0.532 \\
$\mathrm{~A}$ & $0.311^{* * *}$ & $0.412^{* *}$ & 0.493 \\
\hline
\end{tabular}

b) Sex ratios in F2

\begin{tabular}{llcl}
\hline & \multicolumn{3}{c}{ Female parent $(\mathrm{Pl})$} \\
\cline { 2 - 4 } Male & $\mathrm{T}$ & $\mathrm{A}$ \\
$\mathrm{n}$ & $\mathrm{T}$ & $\mathrm{I}$ & 0.446 \\
$\mathrm{~T}$ & $0.442^{*}$ & 0.483 & 0.480 \\
$\mathrm{I}$ & $0.327^{* * *}$ & $0.319^{* * *}$ & 0.470 \\
$\mathrm{~A}$ & $0.381^{* * *}$ & $0.359^{* * *}$ & 0. \\
\hline
\end{tabular}

Experiment 1 was carried out entirely on wheat. To exclude the possibility that foodtype was affecting sex ratio, data were extracted from experiment 2 which involved wheat, sorghum and yellow splitpea. Experiment 2 was not designed specifically to collect sex ratio data; therefore, in order to make results from the two experiments comparable, only data from the first three weeks of oviposition in experiment 2 were used in the analysis. Sex ratios 
Table 2 Sex ratios (proportion male) on wheat, sorghum and yellow split-pea (Experiment 2). The stars represent significance levels of deviations from Ho: $\hat{\mathrm{R}}=0.5$. ( $\left(^{*}: p<\right.$ 0.05 ; $^{* *}: p<0.01$; $\left.^{* *}: p<0.001\right)$

a) Sex ratios from wheat

\begin{tabular}{llll}
\hline & \multicolumn{3}{c}{ Female parent } \\
\cline { 2 - 4 } Male & $\mathrm{T}$ & $\mathrm{I}$ & $\mathrm{A}$ \\
\hline $\mathrm{T}$ & $0.319^{*}$ & 0.466 & 0.494 \\
$\mathrm{I}$ & $0.273^{*}$ & $0.358^{* *}$ & 0.508 \\
$\mathrm{~A}$ & $0.248^{*}$ & $0.386^{*}$ & $0.467^{*}$ \\
\hline
\end{tabular}

b) Sex ratios from sorghum

\begin{tabular}{llll}
\hline \multirow{2}{*}{$\begin{array}{l}\text { Male } \\
\text { parent }\end{array}$} & \multicolumn{3}{c}{ Female parent } \\
\cline { 2 - 3 } & $\mathrm{T}$ & $\mathrm{I}$ & $\mathrm{A}$ \\
\hline $\mathrm{T}$ & 0.452 & 0.513 & $0.426^{* *}$ \\
$\mathrm{I}$ & $0.264^{* * *}$ & 0.343 & 0.511 \\
$\mathrm{~A}$ & $0.242^{* *}$ & 0.388 & 0.484 \\
\hline
\end{tabular}

c) Sex ratios from yellow split-pea

\begin{tabular}{llll}
\hline & \multicolumn{3}{c}{ Female parent } \\
\cline { 2 - 4 } Male & $\mathrm{T}$ & $\mathrm{I} \mathrm{I}^{\dagger}$ & $\mathrm{A}$ \\
\hline $\mathrm{T}$ & 0.388 & - & 0.555 \\
$\mathrm{I} \dagger$ & - & - & - \\
$\mathrm{A}$ & $0.286^{* *}$ & - & 0.527 \\
\hline
\end{tabular}

† The Indian strain was unable to survive on yellow split-pea.

from wheat, sorghum and yellow split-pea are shown in table 2 .

Tables 1 and 2 indicate that on many occasions the sex ratio deviated significantly from 0.5 and that sex ratio bias occurred independently of foodtype. On the whole, sex ratios were biased in favour of females and of the 11 intra-strain sex ratios in tables 1 and 2, 10 were female biased. $S$. oryzae is a weak flier (Kiritani, 1965) and its powers of dispersal are limited. Therefore, like so many pests of stored products, populations are often isolated in grain stores for several generations (Smith and Lessells, 1985). Thus it is possible that populations of $S$. oryzae experience a level of local mate competition (Hamilton, 1967), such that a bias in favour of females is evolutionarily stable (Maynard Smith and Price, 1973); hence the slight sex ratio bias in all strains may be an adaptive trait. The proportion male of all intra-strain cross data pooled was $0 \cdot 444$.

Inspection of the sex ratios in tables 1 and 2 shows that certain categories of inter-strain cross tended to produce significantly biased ratios and that reciprocal crosses differed. Thus the deviations from the mean sex ratio are non-random.

\section{(ii) The model}

Three proximate mechanisms were considered which might account for the observed sex ratio deviations:

a. differential mortality

b. sex linked drive

c. maternally inherited factors.

If males are less likely to survive to adult than females (i.e., differential mortality), then one would expect brood size and proportion male in that brood to be positively correlated, since the more males that die the greater the distortion in the sex ratio and the smaller the brood size. No such correlation was found $(r=-0.41 p>0 \cdot 1)$ (Holloway, 1984).

The sex linked drive model assumed that a male factor and a female factor interacted additively to affect the brood sex ratio. The strength of the male factor (X-linked drive) was fixed for each strain, but varied between strains. The magnitude of the effect of the antagonistic female factor varied between strains in relation to the size of the male effect in the same strain. The direction and degree of bias of the brood sex ratios of inter-strain crosses depended on the relative strengths of the male and female factors carried by the parents. The sex linked model may be interpreted as a test of whether the two sexes are locked in an "arms race", since the male and female factors are assumed to act antagonistically. In other words, the optimum brood sex ratio for the female is not necessarily the sex ratio preferred by the male. The sex linked drive model was examined (Holloway, 1984), but was unable to account for the observed sex ratio data.

In $S$. oryzae the male is the heterogametic sex (Smith, 1952). A model (MI model) was developed involving a maternally inherited, non-chromosomal factor and an independent male factor. The nature of the extrachromosomal agent is not known, but the maternal factor could act either directly on the fertilised eggs (selectively removing those containing a $\mathrm{Y}$ chromosome) or by altering the probabilities that $\mathrm{X}$ and $\mathrm{Y}$-bearing sperm will fertilise eggs (Unterberger and Kirsch, 1932). The data indicate that factors in Trinidad females favoured $\mathrm{X}$ chromosomes the most and African females had least effect on the probability of fertilisation by Y-bearing sperm.

Intra-strain crosses did not produce the most biased sex ratios and therefore the magnitude of 
effect of the male factor of a particular strain seems to vary in relation to the magnitude of effect of the female factor in the same strain. In a sense, the male effect conferred "resistance" to the $\mathrm{Y}$ chromosome against the effect of the female factor. For example, a strong Trinidad male factor would confer resistance to the $\mathrm{Y}$ chromosome against the female factors from all three strains and the sex ratio would reflect the true proportions of $X$ and Y-bearing sperm. If the male factor is not strong enough to confer full resistance to the $\mathrm{Y}$ chromosome, Y-bearing sperm suffer a reduced probability of achieving fertilisation compared with a resistant Y-bearing sperm. A full prediction of resistance and susceptibility of Y-bearing sperm to the maternal effects in all nine strain $\times$ strain combinations is given in table 3 .

Table 3 Prediction of interactive effect of male and female factors on the transmission of ' $Y$ chromosomes to the next generation

a) Relative magnitudes of male and female effects in the threc strains.

\begin{tabular}{lll} 
Strain & Male effect & Female effect \\
\hline T & Strong & Strong \\
I & Medium & Medium \\
A & Weak & Weak
\end{tabular}

b) Predicted response of Y carrying sperm or zygote to female effect encountered.

\begin{tabular}{llll}
\hline Male & & Female parent \\
parent & $\mathrm{T}$ & $\mathrm{I}$ & $\mathrm{A}$ \\
\hline $\mathrm{T}$ & Resistant & Resistant & Resistant \\
$\mathrm{I}$ & Susceptible & Resistant & Resistant \\
$\mathrm{A}$ & Susceptible & Susceptible & Resistant \\
\hline
\end{tabular}

\section{(iii) The analysis}

The data used to test the MI model were those presented in tables $1,2 \mathrm{a}$ and $2 \mathrm{~b}$. The data were fitted by maximum likelihood to the MI model using the GLIM computer package (table 4). The fit of the MI model was compared with a full model $(\mathrm{M}+\mathrm{F}+[\mathrm{M} * \mathrm{~F}])($ table 5$)$ which assumed that the probability that an offspring was male was different in all nine cells of the matrix (table 4a).

Three of the four $F$ values in table 5 are not significant, that is the MI model did not give a significantly worse fit than the full model; thus the MI model provided a reasonable fit to the data. The data producing a significant $F$ value were those from the F2 (table 1b). It can be seen from table
Table 4 MI model fitted by GLIM computer package

$$
\log \frac{\text { Probability male }}{\text { Probability female }}=\mu+m f_{i j}+e_{i j}
$$

where

$$
\begin{aligned}
\mu & =\text { total mean of all data sets } \\
m_{t} & =\text { size of male effect of } i \text { th strain } \\
f_{j} & =\text { size of female effect of } j \text { th strain } \\
e_{i j} & =\text { binomial error term }
\end{aligned}
$$

and

$$
m f_{i j}=0 \text { for } i \leqq j
$$

a) Sex ratio matrix predicted by $\mathrm{MI}$ model

\begin{tabular}{llll}
\hline & \multicolumn{3}{c}{ Female parent } \\
\cline { 2 - 4 } Male & T & I & A \\
Tarent & a & a & a \\
I & b & a & a \\
A & c & d & a
\end{tabular}

\begin{tabular}{|c|c|c|c|c|}
\hline Source & $\mathrm{DF}$ & Deviance & MS & $\mathrm{F}$ \\
\hline $\begin{array}{c}\mathrm{MI}-(\mathrm{M}+\mathrm{F}+ \\
[\mathrm{M} * \mathrm{~F}])\end{array}$ & 5 & $11 \cdot 59$ & $2 \cdot 32$ & $\begin{array}{rl}1.45 & 0.1 \\
<p & <0.25\end{array}$ \\
\hline $\mathrm{M}+\mathrm{F}+[\mathrm{M} * \mathrm{~F}]$ & 96 & $153 \cdot 38$ & $1 \cdot 60$ & \\
\hline MI & 101 & 164.97 & & \\
\hline
\end{tabular}

where $a, b, c, d$ represent the expected sex ratios from the various strain $\times$ strain crosses

Table 5 Comparison of $\mathrm{MI}$ model with full model $(\mathrm{M}+\mathrm{F}+$ $[\mathrm{M} * \mathrm{~F}])$

\begin{tabular}{|c|c|c|c|c|}
\hline $\begin{array}{l}\mathrm{MI}-(\mathrm{M}+\mathrm{F} \\
\quad+[\mathrm{M} * \mathrm{~F}])\end{array}$ & 5 & $18 \cdot 41$ & $3 \cdot 68$ & $\begin{array}{l}1.780 .1 \\
<p<0.25\end{array}$ \\
\hline $\mathbf{M}+\mathbf{F}+[\mathbf{M} * \mathbf{F}]$ & 42 & $86 \cdot 76$ & $2 \cdot 07$ & \\
\hline MI & 47 & $105 \cdot 17$ & & \\
\hline \multicolumn{5}{|c|}{ d) Data from sorghum (table $2 b$ ) } \\
\hline $\begin{array}{l}\mathrm{MI}-(\mathrm{M}+\mathrm{F} \\
\quad+(\mathrm{M} * \mathrm{~F} \mid)\end{array}$ & 5 & $17 \cdot 56$ & $3 \cdot 51$ & $\begin{array}{rl}1.84 & 0.1 \\
<p & <0.25\end{array}$ \\
\hline$M+F[M * F]$ & 41 & $78 \cdot 21$ & 1.91 & \\
\hline MI & 46 & $95 \cdot 77$ & & \\
\hline
\end{tabular}

a) Data from F1 (Table la)

b) Data from F2 (table 1b)

$\begin{array}{lrrrr}\mathrm{MI}-(\mathrm{M}+\mathrm{F} & 5 & 32.25 & 6.45 & 3.190 .005 \\ +[\mathrm{M} * \mathrm{~F}]) & & & & <p<0.01 \\ \mathrm{M}+\mathrm{F}+[\mathrm{M} * \mathrm{~F} \mid & 148 & 299.09 & 2.02 & \\ \mathrm{MI} & 153 & 331.34 & & \end{array}$

c) I)ata from wheat (table 2a)

$1 \mathrm{~b}$ that the sex ratio not fitting the MI model is that associated with $I \times I$ cross. To test whether the $I \times I$ sex ratio was the only one not fitting the MI model, the model was modified so that Indian 
Y-bearing sperm were susceptible to the Indian maternal factor. In other words, the matrix in table 4 a now reads with a letter e corresponding to the I $\times$ I combination. The data from the F2 (table $1 \mathrm{~b}$ ) were fitted to the modified maternal inheritance model (MIM model) (table 6).

Table 6 Comparison of MiM model with full model $(\mathrm{M}+\mathrm{F}+$ $[\mathrm{M} * \mathrm{~F}])$ for $\mathrm{F} 2$ data (table $1 \mathrm{~b}$ )

\begin{tabular}{|c|c|c|c|c|c|}
\hline Source & DF & Deviance & MS & $\mathrm{F}$ & \\
\hline $\begin{array}{c}\mathrm{MIM}-(\mathrm{M}+\mathrm{F} \\
[\mathrm{M} * \mathrm{~F})]\end{array}$ & 4 & $3 \cdot 79$ & 0.95 & 0.47 & $0.25<p$ \\
\hline $\mathrm{M}+\mathrm{F}+[\mathrm{M} * \mathrm{~F}]$ & 148 & $299 \cdot 09$ & $2 \cdot 02$ & & \\
\hline MIM & 152 & $302 \cdot 88$ & & & \\
\hline
\end{tabular}

The MIM model did not give a significantly worse fit than the full model. Thus the $I \times I$ sex ratio in the $F 2$ (table $1 \mathrm{~b}$ ) was the only sex ratio not fitting the MI model. No reason could be given why the $\mathrm{I} \times \mathrm{I}$ cross produced a significantly biased sex ratio in the $F 2$.

\section{DISCUSSION}

The good fit of the maternal inheritance (MI) model to the data provides evidence of independent male and female factors which interact to affect the sex ratio in $S$. oryzae. The female effect seems to be inherited as a maternal, non-chromosomal factor, but the data do not allow further speculation as to the nature of the maternal factor.

Since an independent male factor is intrinsic to the MI model, the involvement of the $\mathrm{Y}$ chromosome is necessary. In many organisms, the $\mathrm{Y}$ linked genes appear to be non-functional, possibly reflecting the operation of Müller's ratchet (Müller, 1964; Felsenstein, 1974). Theoretical models have been developed concerning the evolution of inert Y chromosomes (Nei, 1970; Charlesworth, 1978) and Hamilton (1967) suggested that $Y$ chromosomes are genetically inert as a defence against the dangers of Y-linked drive.

The sex determination mechanism in $S$. oryzae is a neo-XY system (Smith, 1952). The neo-XY system in $S$. oryzae is thought to have developed from an Xy system, having a minute y chromosome, as is still found in the closely related species $S$. granarius. Neo-XY sex determination mechanisms usually develop from $\mathrm{XO}$ (or $\mathrm{Xy}$ ) systems thought the centric fusion of an acrocentric $X$ chromosome and an acrocentric autosome (White, 1973). If the fusion spreads through the popula- tion, the unfused autosome is then limited to the male and is termed the neo-Y chromosome. Presumably, since crossing over between the neo-X and neo-Y chromosomes in $S$. oryzae is very restricted (Smith, 1952), Müller's ratchet is operating and slowly increasing the genetic load associated with the neo-Y chromosome (Haldane, 1957; Lewontin, 1974). In time, the neo-Y chromosome in $S$. oryzae may evolve to become dysfunctional (MaynardSmith, 1978). However, much of the neo-Y chromosome in $S$. oryzae stains euchromatically (Smith, 1952), indicating the presence of func.. tional genes which may include a chromosomally inherited male factor on the neo-Y chromosome affecting sex ratio.

Several aspects of the MI model resemble the phenomenon of hybrid dysgenesis in Drosophila (Kidwell et al., 1977; Engels, 1979; Kidwell, 1979). Hybrid dysgenesis is a term used to describe a syndrome of aberrant traits observed when certain strains of Drosophila spp. are crossed. The underlying nature of hybrid dysgenesis is not well understood, but hypotheses have been formulated in terms of transmissible, but probably not Mendelian, factors (Kidwell and Kidwell, 1976; Picard, 1976). One factor is passed on by the male and another by the female; their interaction leads to dysgenesis (Kidwell and Kidwell, 1976). Since separate male and female factors are involved, reciprocal crosses do not always yield similar results, as found in the present study. One of the traits encompassed in the syndrome is the distortion of transmission ratios, which may manifest itself as a biased sex ratio.

There is evidence of maternally inherited factors affecting sex ratio in other organisms. Goldschmidt (1931) found that the sex ratio of the gypsy moth, Lymantria dispar L., was affected by a maternally inherited factor, and certain types of sex ratio bias in Drosophila spp. are known to be caused by agents (often spirochaetes) passed on through the öoplasm (Malagolowkin et al., 1959; Poulson and Sakaguchi, 1961). It is known that symbiotic relationships exist betwen micro-organisms and insects with a restricted diet deficient in certain essential nutrients (Chapman, 1971, chapter 5), including Coleoptera surviving on dry cereal (e.g., $S$. oryzae). In some beetles, micro-organisms are inherited by the offspring from the mother via the öoplasm (Brooks, 1963). It is possible that the sex ratio is affected in $S$. oryzae by micro-organisms transmitted maternally giving a maladaptive sex ratio bias and that the male effect (in the MI model) has evolved to correct the maternally determined sex ratio bias. 
Acknowledgements I would like to thank Dr R. H. Smith for his constructive criticisms and careful reading of the manuscript, Dr J. H. Roger for his advice concerning the statistical analysis and Professor K. Simkiss for providing research facilities. The Indian and African strains of $S$. oryzae were provided by Dr P. Dobie of the Tropical Development Research Institute (Slough) and the Trinidad strain was collected by Dr R. H. Smith on a visit to Trinidad funded by the British Council. The work was part of a project funded by a NERC studentship.

\section{REFERENCES}

BROOKS, M. A. 1963. Symbiosis and aposymbiosis in arthropods, Symp. Soc. genetic. Micro-biol., 13, 200-231.

CHAPMAN, R. F. 1971. The Insects: Structure and Function (2nd edn.). Hodder and Stoughton, London.

CHARLESWORTH, B. 1978. Model for evolution of Y chromosomes and dosage compensation. Proc. Natl. Acad. Sci., USA, 75, 5618-5622.

CHARNOV, E. L. 1982. The Theory of Sex Allocation. Princeton University Press, Princeton.

COOMBS, (. W. Billings, C. J. ANI) PORTER, J. E. 1977. The effect of yellow split-peas (Pisum sativum) and other pulses on the productivity of certain strains of Sitophilus oryzae and the ability of other strains to breed thereon. $J$. stored Prod. Res., 13, 53-58.

ENGELS, W. R. 1979. Hybrid dysgenesis in Drosophila melanogaster: rules of inheritance of female sterility. Genet. Res., 3.3, 219-236.

EVANS, D. E. 1977. The capacity for increase at low temperatures of several Australian populations of Sitophilus oryzae (L.). Aust. J. Ecol., 2, 55-67.

FELSHNSTEIN, J. 1974. The evolutionary advantage of recombination. Genetics, 78, 737-756.

FISHER, R. A. 1930. The Genetical Theory of Natural Selection. Oxford University Press, Oxford

GOLDSCHMIIT, R. 1931. Analysis of intersexuality in the Gypsy Moth. Quart. Rev. Biol., 6, 125-142.

HAI.DANE, J. B. S. 1957. The cost of natural selection. J. Genet., $55,511-524$

HALSTEAI), (i. H. 1963. External sex differences in stored products Coleoptera. Bull. ent. Res., 54, 119-134.

HAMILTON, W. D. 1967. Extraordinary sex ratios. Science, 156, 477-488.

HOLloway, (i. J. 1984. Genetic differentiation and life history variation in the rice weevil, Sitophilus oryzae. PhD Thesis, Reading University.

KIDWELL, M. (i. 1979. Hybrid dysgenesis in Drosophila melanogaster: the relationship between the P-M and I-R interaction systems. Genet. Res., 33, 205-217.
KIDWELL, M. G. AND KIDWELl, J. F. 1976. Selection for male recombination in Drosophila melanogaster. Genetics, 84 , 333-351.

KIIJWEI.L, M. G., KIDWELL, J. F. AND SVED, J. A. (1977). Hybrid dysgenesis in Drosophila melanogaster: a syndrome of aberrant traits including mutation, sterility and male recombination. Genetics, 86, 813-833.

KIRITANI, K. 1965. Biological studies on the Sitophilus complex in Japan. J. stored Prod. Res., 1, 169-176.

LEWONTIN, R. C. 1974. The Genetic Basis of Evolutionary Change. Columbia University Press, New York

MALAGOLOWKIN, C., POULSON, D. F. AND WRIGHT, E. Y. 1959. Experimental transfer of maternally inherited abnormal sex ratio in Drosophila willistoni. Genetics, 44, 59-74.

MAYNARI) SMITH, I. 1978. The Evolution of Sex. Cambridge University Press, Cambridge.

MAYNARD SMITH, J. AND PRICE, (j. R. 1973. The logic of animal conflict. Nature, Lond., 246, 15-18.

MÜLLER, H. I. 1964. The relation of recombination to mutational advance. Mutation Res., 1, 2-9.

NEI, M. 1970. Accumulation of non-functional genes on sheltered chromosomes. Amer. Nat., 104, 311-321.

PIC:ARI), (i. 1976. Non-Mendelian female sterility in Drosophila melanogaster: Hereditary transmission of I factor. Genetics, $83,107-123$

PIXTON, S. W. ANI) WARBURTON. S. 1968. The iime required for conditioning grain to equilibrium with specific relative humidities. J. stored Prod. Res., 4, 261-265.

POULSON, D. F. ANI) SAKA(iUs(HI, B. 1961. Nature of "sex ratio" agent in Drosophila. Science, 133, 1489-1490.

RICHARDS, O. W. 1947. Observations on grain weevils Calandra (Col. Curculionidae). I General biology and oviposition. Proc. Zool. Soc. Lond., 117, 1-43.

SHAZALI, M. E. H. 1982. The biology and population ecology of four insect pests of stored" sorghum with particular reference to competition and succession. PhD Thesis, Reading University.

SIN(;H, S. R. ANI) SOIDERSTROM, E. L. 1963. Sexual maturity of the rice weevil Sitophilus oryzae as indicated by sperm transfer and viable eggs. J. Kansas Entomol. Soc., 36, 32-34.

SMITH, S. G. 1952. The cytology of Sitophilus (Calandra) oryzae, $S$. granarius and some other Rynchophora (Coleoptera). Cytologia, 17, 50-70.

SMITH, R. H. AND LESSFL.LS, ( $\therefore$ M. 1985. Oviposition, ovicide and larval competition in granivorous insects. In Behavioural Ecology (Eds R. M. Sibly and R. H. Smith). Blackwell, Oxford.

UNTERBURGER, F, AND KIRSC:H, W. 1932. Bericht ïber versuche zur beeinflussung des geschlechtsverhältnisses bei kanin chen nach Unterburger. Monatschr. $f$. Geburtschülfe u. Gynäkologie, 91, 17-27.

White, M. J. D. 1973. Animal Cytology and Evolution (3rd ed.). Cambridge University Press, Cambridge. 